TAKAHASHI K; CARDOSO AII. 2015. Produção e qualidade de mini tomate em sistema orgânico com dois tipos de condução de hastes e poda apical. Horticultura Brasileira 33: 515-520 DOI - http://dx.doi.org/10.1590/S0102-053620150000400018

\title{
Produção e qualidade de mini tomate em sistema orgânico com dois tipos de condução de hastes e poda apical
}

\author{
Keiko Takahashi; Antonio II Cardoso \\ Universidade Estadual Paulista (UNESP), Botucatu-SP, Brasil; keiko.pontealta@gmail.com; ismaeldh@fca.unesp.br
}

\section{RESUMO}

O tomate é uma das dez hortaliças com maior acúmulo de dados agronômicos. No entanto, apesar da grande importância do manejo cultural na produtividade do tomateiro, ainda há carência de pesquisa no cultivo de mini tomate. Neste sentido, o presente trabalho teve objetivo de avaliar o efeito da poda apical e condução de hastes em plantas de mini tomate enxertadas, cultivadas no sistema orgânico, sobre a produção e qualidade dos frutos. O experimento foi conduzido em Itatinga-SP. O delineamento experimental utilizado foi de blocos ao acaso, com quatro tratamentos, 16 repetições e quatro plantas úteis por parcela. Os tratamentos foram resultantes do fatorial $2 \times 2$, sendo dois tipos de condução de hastes (duas hastes: haste principal e uma haste secundária conduzida imediatamente abaixo do primeiro cacho da haste principal, denominada de condução tradicional; ou duas hastes secundárias conduzidas a partir das gemas localizadas nas axilas das duas primeiras folhas localizadas imediatamente após o ponto de enxertia, denominada de condução de "hastes baixeiras") e dois tipos de poda apical (três ou cinco folhas entre a poda apical e o último cacho). A condução de duas "hastes baixeiras" foi superior à tradicional para número de cachos por planta $(18,4 \mathrm{x}$ $16,4)$, produção total $(2,61 \times 2,29 \mathrm{~kg})$ e comercial $(2,09 \times 1,76 \mathrm{~kg})$ por planta, número de frutos totais $(318 \times 283)$ e comerciais $(226 \mathrm{x}$ 188) por planta e porcentagem de aproveitamento $(79,2 \times 76,2 \%)$. O número de folhas deixado entre a poda apical e o último cacho não influenciou as características avaliadas. $\mathrm{O}$ teor de sólidos solúveis não foi afetado pelos fatores estudados, com média de $7,05^{\circ}$ Brix. Com base nos resultados obtidos é possível concluir que a condução de duas "hastes baixeiras" foi superior à tradicional, com maior produção de frutos comerciais.

Palavras chave: Solanum lycopersicum, sistema de condução, cultivo orgânico.

\begin{abstract}
Production and quality of mini tomato in organic system with two stems conduction and top pruning

Tomato is among the ten vegetable species with higher agronomic data published. However, despite the great importance of cultural practices on tomato yield, there is still lack of research on mini tomato cultivation. Therefore, the present study had the objective to evaluate the effect of top pruning and stem conduction of grafted mini tomato plants, cultivated in organic system, on yield and fruit quality. The experiment was set up in the municipality of Itatinga, São Paulo State, Brazil. The experimental design used was of completely randomized blocks, with four treatments, 16 replications and four plants per plot. Treatments were resultant from factorial $2 \times 2$, with two stem conduction types (two stems: main stem plus secondary stem conducted immediately under the first cluster of main stem, named as traditional conduction; or two secondary stems conducted from axillary buds of the two leaves immediately above the grafting point, named as "bottom stem conduction") and two types of top pruning (three or five leaves between the top pruning and the last cluster). "Bottom stem conduction" was superior to traditional one for cluster number per plant $(18.4 \times 16.4)$, total $(2.61 \times 2.29 \mathrm{~kg})$ and marketable $(2.09 \times 1.76 \mathrm{~kg})$ production per plant, total $(318 \times 283)$ and marketable $(226 \times 188)$ fruit number per plant and utilization percentage $(79.2 \mathrm{x}$ $76.2 \%$ ). Leaves number left between top pruning and the last cluster did not influence the characteristics evaluated. Soluble solids content was not affected by studied factors, with average of $7.05^{\circ}$ Brix. Based on the results obtained it is possible to conclude that the conduction of two "bottom" stems was superior to traditional conduction, with higher production of marketable fruits.
\end{abstract}

Keywords: Solanum lycopersicum, management system, organic crop.

(Recebido para publicação em 12 de agosto de 2014; aceito em 10 de abril de 2015)

(Received on August 12, 2014; accepted on April 10, 2015)

$\mathrm{O}$ tomateiro (Solanum lycopersicum) é uma hortaliça cultivada em praticamente todas as regiões do Brasil e apreciada no mundo todo. Segundo a FAO (2012), a produção mundial de tomate no ano de 2012 foi de 161,79 milhões de toneladas, sendo o Brasil o oitavo maior produtor com 3,87 milhões de toneladas. De acordo com o AGRIANUAL (2013), duas décadas atrás a produtividade brasileira de tomate era de 41,02 t/ha e no ano de 2012 foi de $63,54 \mathrm{t} / \mathrm{ha}$, ou seja, houve um aumento de $54,9 \%$ durante esse período.

A cadeia produtiva de tomate de mesa vem experimentando importantes transformações orientadas para a sua modernização e aumento da produtividade (Matos et al., 2012). O incremento na produtividade do tomateiro deveu-se a vários fatores e, dentre eles, podem ser destacados o uso de cultivares altamente produtivas, que são na maioria das vezes híbridos; otimização no uso da área, com 
o plantio de cultivares que permitem o cultivo mais adensado; utilização de enxertia, que permitiu o cultivo do tomateiro em áreas infestadas por patógenos de solo e salinizadas, principalmente em cultivo protegido; desenvolvimento de práticas culturais tais como a poda apical que permitiu maior produção num menor período de cultivo e a condução de mais de uma haste por planta que, além de ter aumentado a produtividade, diminuiu o custo de produção.

Além da alta produtividade, muitos produtores vêm buscando genótipos com características diferenciadas, tais como alto teor de sólidos solúveis, tamanho, formato e cor que se destaquem em relação ao padrão tradicional. Tais buscas visam atender um mercado consumidor que está se tornando cada dia mais exigente. $\mathrm{O}$ tomate tipo mini, considerado um produto diferenciado, foi introduzido no Brasil há aproximadamente duas décadas e a sua demanda tem aumentado no decorrer dos anos devido ao seu excelente sabor, cor e formato variados, podendo assim ser utilizado na ornamentação de pratos e saladas (Filgueira, 2008; Alvarenga, 2013).

Quase todas as cultivares de mini tomate comercializadas no Brasil são de crescimento indeterminado. Estas são exigentes em alguns tipos de podas, tais como a desbrota, que consiste na retirada frequente dos brotos laterais, e a poda apical (desponta ou capação), que é a retirada do meristema apical da haste, contendo o crescimento vegetativo e diminuindo o número de cachos. Com a poda apical há redução no número de frutos, porém aqueles já formados desenvolvem-se mais e ganham mais peso (Machado et al., 2007; Filgueira, 2008). Estas práticas também facilitam a execução dos tratos culturais, reduzem a quantidade e aumentam a segurança na aplicação de defensivos e melhoram a qualidade dos frutos (Guimarães et al., 2007; Machado et al., 2007; Filgueira, 2008; Alvarenga, 2013).

Apesar da grande importância do manejo das plantas na produtividade do tomateiro do grupo de mini tomates, ainda há carência de informações a respeito de poda apical e condução de hastes. Desta forma, objetivou-se com o presente trabalho avaliar o efeito da poda apical e da condução de hastes em plantas de mini tomate enxertadas, cultivadas no sistema orgânico, sobre a produção e qualidade dos frutos.

\section{MATERIAL E MÉTODOS}

O experimento foi conduzido na Fazenda Santa Terezinha do Rio Bonito, situada no município de Itatinga-SP (2306'06'S, 48 36'57'O, altitude 845 metros). De acordo com a classificação climática de Köppen-Geiger, a região é do tipo Cwa que é caracterizado por clima temperado úmido com inverno seco e verão quente (Peel et al., 2007). A fazenda possui certificação orgânica desde 2006 e atualmente a entidade que a certifica é a ECOCERT Brasil.

A estufa agrícola onde o experimento foi conduzido é do tipo arco, coberta com filme de polietileno de $150 \mu \mathrm{m}$ de espessura, laterais com tela antiafídeo, comprimento de $31,5 \mathrm{~m}$, largura de 6,4 $\mathrm{m}$, pé-direito de $4,0 \mathrm{~m}$ e altura total no centro da estufa de 5,5 m.

Para a caracterização do solo onde o experimento foi conduzido foram coletadas amostras nas profundidades de $0 \mathrm{a}$ $20 \mathrm{~cm}$ e 20 a $40 \mathrm{~cm}$. Nas profundidades de 0 a $20 \mathrm{~cm}$ e 20 a $40 \mathrm{~cm}$, respectivamente, foram obtidos os resultados: $\mathrm{pH}\left(\mathrm{CaCl}_{2}\right)=6,0$ e 4,$8 ; \mathrm{P}_{\text {resina }}=12$ e $4 \mathrm{mg} /$ $\mathrm{dm}^{3}$; matéria orgânica $=21$ e $16 \mathrm{~g} / \mathrm{dm}^{3}$; $\mathrm{V}=68$ e $32 \%$; e os valores de $\mathrm{Al} ; \mathrm{H}$; $\mathrm{Na}$; $\mathrm{K}$; $\mathrm{Ca}$; $\mathrm{Mg}$; $\mathrm{SB}$ e CTC, expressos em $\mathrm{mmol} / \mathrm{dm}^{3}$, foram respectivamente $0 \mathrm{e}$ $2 ; 16$ e $29 ; 0,3$ e 0,$1 ; 1,5$ e 0,$6 ; 20$ e 8 ; 12 e $6 ; 33,8$ e 14,7; 49,8 e 45,7.

O preparo do solo foi realizado do modo como é usualmente feito para as áreas de produção da fazenda Santa Terezinha. Uma semana antes do transplantio, o solo foi preparado com encanteiradeira na profundidade de $20 \mathrm{~cm}$. Foram aplicados à lanço, em kg/ha, 264 de $\mathrm{N}, 361$ de $\mathrm{P}_{2} \mathrm{O}_{5}, 83$ de $\mathrm{K}_{2} \mathrm{O}, 573$ de $\mathrm{Ca}, 103$ de $\mathrm{Mg}, 15$ de S, 1,2 de B; de Mo foram aplicados 89,5 g/ha. Os nutrientes foram fornecidos com aplicação de bokashi, sendo a quantidade de fósforo complementada pelo Yoorin Master ${ }^{\circledR}$ e de cálcio pelo Alfértil ${ }^{\circledR}$ ( $32 \%$ de Ca). Os canteiros, com 29,5 m de comprimento, $70 \mathrm{~cm}$ de largura e $20 \mathrm{~cm}$ de altura, fo- ram cobertos com filme de polietileno preto com espessura de $17 \mu \mathrm{m}$.

O delineamento experimental utilizado foi de blocos ao acaso, com quatro tratamentos e 16 repetições. Cada parcela foi constituída por uma linha de seis plantas, sendo que as quatro plantas centrais da parcela foram consideradas como úteis. Os tratamentos foram resultantes do esquema fatorial $2 \times 2$, sendo dois tipos de condução de hastes (duas hastes: haste principal e uma haste secundária conduzida imediatamente abaixo do primeiro cacho da haste principal, denominada de condução tradicional; ou duas hastes secundárias conduzidas a partir das gemas localizadas nas axilas das duas primeiras folhas localizadas imediatamente após o ponto de enxertia, denominada de condução de "hastes baixeiras") e dois tipos de poda apical (três ou cinco folhas entre a poda apical e o último cacho). A poda apical ("capação") das hastes produtivas foi realizada quando estas atingiram o arame de sustentação dos fitilhos a aproximadamente, $4 \mathrm{~m}$ de altura. Considerando-se que há a emissão de uma inflorescência a cada três folhas (Tanaka \& Fujita, 1974), para os tratamentos com cinco folhas foi retirada a inflorescência desenvolvida entre estas folhas.

Foi utilizado como enxerto o híbrido Sweet Grape da empresa Sakata Seed. Como porta-enxerto utilizou-se o híbrido Guardião, da empresa Takii Seeds. A enxertia, para todos os tratamentos, foi realizada pelo método de garfagem tipo fenda cheia.

A semeadura foi realizada em bandejas de poliestireno expandido de 128 células preenchidas com substrato orgânico à base de fibra de coco. Dez dias após a enxertia, as mudas foram transferidas para vasos com capacidade de $400 \mathrm{~mL}$ preenchidos com o mesmo substrato, visando não restringir o seu desenvolvimento antes do transplantio para o local definitivo, e realizou-se a poda do meristema apical da haste principal nas mudas dos tratamentos com condução de duas "hastes baixeiras". Esta poda foi feita logo após a terceira folha após o ponto de enxertia. Desta maneira, foram emitidas duas hastes logo abaixo desta poda, localizadas logo após o ponto de enxertia, ainda na fase 
de viveiro.

O transplantio para o solo na estufa foi realizado em 08/12/2011. O espaçamento utilizado foi de $1,6 \mathrm{~m}$ entre as linhas de plantio e $0,3 \mathrm{~m}$ entre as plantas. Os tomateiros foram tutorados com fitilhos presos a arames esticados horizontalmente a $4 \mathrm{~m}$ de altura, sendo um fitilho para cada haste.

Para cada canteiro a irrigação foi realizada por duas linhas de tubos gotejadores com vazão de $6,02 \mathrm{~L} / \mathrm{h} / \mathrm{m}$, com emissores espaçados $30 \mathrm{~cm}$ entre si. A adubação de cobertura consistiu de três aplicações mensais de bokashi próximo à base das plantas, sendo a primeira realizada 30 dias após o transplantio.

O controle de pragas (Tuta absoluta, Neoleucinodes elegantalis e Aculops lycopersici) foi realizado utilizando-se placas amarelas com cola; inimigo natural Trichograma pretiosum, na população de soltura de 360 mil parasitoides/ha/semana, a partir da data do transplantio; Dipel ${ }^{\circledR}$, produto a base de Bacillus thuringiensis, na dosagem de um grama por litro e aplicações semanais a partir da data do transplantio; e Kumulus $^{\circledR}$, produto contendo $80 \%$ de enxofre elementar, na dosagem de $2 \mathrm{~g} / \mathrm{L}$, semanalmente a partir do aparecimento da praga ou doença.

As colheitas foram realizadas uma vez por semana com os frutos apresentando a coloração vermelha, de 30/01a 02/04/2012.

Foram avaliados os caracteres número de cachos nas plantas; produção (massa) e número total e comercial de frutos (com massa fresca superior a cinco gramas, sem sintomas de doenças, pragas, fundo preto, rachadura ou manchas); número de frutos por cacho; produção de frutos atacados por pragas (\%), descarte (frutos não comerciais) e aproveitamento (comerciais); massa fresca média dos frutos totais e comerciais; diâmetro, comprimento e teor de sólidos solúveis dos frutos comerciais.

A produção de frutos atacados por pragas (\%) foi determinada pela razão da massa fresca dos frutos com sintomas de ataque de pragas pela massa fresca total dos frutos da parcela. A porcentagem de aproveitamento e de descarte foi determinada pela razão da massa fresca dos frutos comerciais e não comerciais, respectivamente, pela massa fresca total dos frutos da parcela.

O diâmetro e o comprimento dos frutos comerciais foram determinados por amostragem onde, em cada colheita foram retirados ao acaso 15 frutos comerciais por parcela e medidos o diâmetro na região mediana e o comprimento com auxílio de paquímetro. O teor de sólidos solúveis (TSS) foi determinado nos frutos amostrados para medição do diâmetro e comprimento, com a utilização de refratômetro portátil marca Atago modelo MT032ATC com compensação automática de temperatura. Os resultados foram expressos em ${ }^{\circ}$ Brix.

Os dados foram submetidos à análise de variância utilizando-se o programa Sanest e, quando houve diferenças entre os tratamentos, as médias foram comparadas pelo teste de Tukey a 5\% de probabilidade. Os dados referentes aos caracteres número de frutos (total e comercial) foram transformados de acordo com $\sqrt{\mathrm{x}}$ e os referentes à porcentagem (aproveitamento, descarte e atacados por pragas) foram transformados em $\log \mathrm{x}$.

\section{RESULTADOS E DISCUSSÃO}

O fator poda apical e a interação entre os fatores condução das hastes e poda apical não foram significativos pelo teste $\mathrm{F}$ para todos os caracteres. Já para o fator condução das hastes foram obtidos valores de F significativos a 5\% para a maioria dos caracteres.

$\mathrm{Na}$ condução com duas "hastes baixeiras", a primeira inflorescência era emitida após 5-6 folhas. Já nos tratamentos com condução tradicional a emissão da primeira inflorescência ocorreu após 9-10 folhas. Esta é a razão dos tratamentos com duas "hastes baixeiras" apresentarem um ganho de aproximadamente dois cachos por planta (Tabela 1), o que corresponde a um incremento de $11,5 \%$ na produção de cachos, com média de 9,2 e 8,2 cachos por haste na condução de duas "hastes baixeiras" e tradicionais, respectivamente. Observa-se que a poda apical (número de folhas) não influenciou este caráter, com 17,6 e 17,3 cachos por planta quando três e cinco folhas foram deixadas antes da poda apical, respectivamente.
No tratamento em que foram conduzidas duas "hastes baixeiras" a produção total foi de 2,61 kg/planta, 13,8\% superior em relação ao tratamento onde se utilizou a condução tradicional dos produtores de tomate de mesa, que produziu 2,29 kg/planta (Tabela 1). Segundo Logendra et al. (2001), a produção em tomateiro é diretamente proporcional ao número de frutos. Este foi maior no tratamento onde foram conduzidas duas "hastes baixeiras", que produziram $12,3 \%$ a mais de frutos totais e $20,2 \%$ a mais de frutos comerciais que as plantas do tratamento com condução tradicional. Este aumento do número de frutos se deve à maior quantidade de cachos produzidos, pois não foi observada diferença no número de frutos por cacho (Tabela 1).

Os tratamentos com condução tradicional das hastes apresentaram maior proporção de frutos atacados por pragas que os tratamentos com condução de duas "hastes baixeiras" (Tabela 1). Observou-se que, após aproximadamente 74 dias do transplantio, alguns insetos pragas já estavam presentes atacando as plantas, principalmente a traça e a broca pequena do fruto. Esse ataque foi se intensificando, com o seu pico observado ao final do ciclo das plantas, sendo que na última colheita cerca de $50 \%$ dos frutos colhidos estava danificados.

Para o caráter porcentagem de descarte foram contabilizados os frutos atacados por pragas, rachados, manchados, com massa inferior a cinco gramas e com fundo preto. A quantidade de frutos apresentando os quatro últimos defeitos individualmente foi pequena e a de frutos atacados por pragas foi a que mais contribuiu para este caráter (aproximadamente 50\% dos frutos não comerciais). Portanto, a maior porcentagem de descarte observada nos tratamentos com condução tradicional foi devida à maior quantidade de frutos atacados por pragas (Tabela 1).

A maior quantidade de frutos atacados por pragas associada à maior porcentagem de descarte refletiu na menor porcentagem de aproveitamento no tratamento com condução tradicional das hastes. Nesse tratamento houve um decréscimo de $3 \%$ na porcentagem de aproveitamento quando comparado com 
o tratamento de duas "hastes baixeiras" (Tabela 1). No entanto, a poda apical não teve influência sobre as porcentagens de frutos atacados por pragas, de descarte e de aproveitamento.

No tratamento conduzido com duas "hastes baixeiras" houve um aumento de $18,45 \%$ na produção comercial por planta quando comparado ao tratamento onde foi utilizada a condução tradicional das hastes. O mesmo ocorreu para o número de frutos comerciais por planta. A maior produção comercial do tratamento em que se conduziram duas "hastes baixeiras" está relacionada com a maior produção total de frutos (Tabela 1) e com a menor porcentagem de frutos atacados por pragas e, consequentemente, com a maior porcentagem de aproveitamento.

$\mathrm{O}$ número de folhas deixado entre o último cacho e a capação não afetou a produção de frutos total e comercial, tanto em massa como em número por planta (Tabela 1). Estes resultados diferem dos obtidos por Logendra et al. (2001) que observaram, para a cultivar Laura, uma tendência de aumento na produção por planta quando são deixadas nenhuma, uma ou duas folhas após o cacho em plantas cultivadas com cacho único. Os autores observaram que esse aumento foi significativo quando foram deixadas duas folhas em comparação a nenhuma no inverno, e duas em comparação a nenhuma ou uma folha na primavera. $\mathrm{O}$ aumento na produção foi de aproximadamente $25 \%$ quando duas folhas foram deixadas, em comparação a nenhuma, tanto no inverno quanto na primavera. Esse efeito de aumento da produção foi devido ao ganho de massa fresca dos frutos. Este fato não foi observado no presente experimento, provavelmente pelo maior número de cachos (17,5 por planta) e, consequentemente, de frutos (drenos), com média de 300 por planta, fazendo com que o possível efeito do ganho de massa por fruto fosse diluído entre todos os frutos, enquanto Logendra et al. (2001) trabalharam com cacho único, tendo o número de drenos limitado.

Por outro lado, os resultados obtidos para o caráter número total de frutos também estão de acordo com os resultados obtidos por Logendra et al. (2001) que não obtiveram diferença para o número de frutos quando foram deixadas nenhuma, uma ou duas folhas após o cacho.

A poda apical também não afetou a produção comercial, o número de frutos comerciais por planta e o número de frutos por cacho (Tabela 1), sendo que, em média, os resultados obtidos foram 1,92 kg/planta, 207 frutos/planta e 16,3 frutos/cacho respectivamente.

Observa-se que a massa fresca média dos frutos totais das plantas conduzidas de forma tradicional foi superior à dos frutos provenientes das plantas que tiveram suas hastes conduzidas de forma baixeira (Tabela 2). Esse efeito foi, provavelmente, devido ao menor número de cachos por planta produzidos nesse tratamento (Tabela 1) proporcionando, dessa forma, maior disponibilidade de fotoassimilados para cada fruto individualmente, reforçando o que foi obtido no trabalho conduzido por Mueller \& Wamser (2009) que relatam que a massa fresca dos frutos diminui conforme o aumento no número de cachos na planta.

De acordo com Mueller \& Wamser (2009), o aumento na densidade de plantio está correlacionado positivamente com a produção, mas negativamente com o tamanho do fruto devido ao suprimento insuficiente de fotoassimilados para cada fruto. Abrahão et al. (2014), estudando este mesmo híbrido Sweet Grape, na densidade de 3,33 plantas $/ \mathrm{m}^{2}\left(1,25\right.$ plantas $/ \mathrm{m}^{2}$ a mais que no presente trabalho) e condução de uma haste, obtiveram 1,30 kg/planta e frutos com massa fresca de 9,0 g. No presente estudo observou-se que com menor densidade populacional, porém conduzindo-se maior número de hastes obteve-se maior produção (Tabela 1) sem que houvesse perda de massa dos frutos (Tabela 2). Charlo et al. (2009) também observaram que a condução de duas hastes por planta para o híbrido Alambra resultou em maior produção por planta do que apenas uma haste. Dessa forma a condução de duas hastes por planta mostra-se vantajosa, pois

Tabela 1. Número de cachos por planta (NCP), produção total (PT) e comercial (PC), número de frutos total (NFT) e comercial (NFC) por planta, número de frutos por cacho (NFPC), produção de frutos atacados por pragas (\%) (PAP), descarte (PD) e aproveitamento (PA) de plantas de mini tomate submetidas a dois tipos de condução das hastes e duas podas apicais \{cluster number per plant (NCP), total (PT) and marketable (PC) production, total (NFT) and marketable (NFC) fruit number per plant, fruit number per cluster (NFPC), fruit production affected by pests (\%) (PAP), discarded (PD) and utilization (PA) of mini tomato plants submitted to two stem conduction types and two top prunings $\}$. Itatinga, UNESP, 2012.

\begin{tabular}{|c|c|c|c|c|c|c|c|c|c|}
\hline \multirow{2}{*}{$\begin{array}{l}\text { Condução das } \\
\text { hastes }\end{array}$} & \multirow{2}{*}{ NCP } & PT & $\mathbf{P C}$ & \multirow{2}{*}{ NFT } & \multirow{2}{*}{ NFC } & \multirow{2}{*}{ NFPC } & \multirow{2}{*}{\multicolumn{3}{|c|}{$\begin{array}{c}\text { PD } \\
(\%)\end{array}$}} \\
\hline & & \multicolumn{2}{|c|}{ (kg/planta) } & & & & & & \\
\hline Tradicional & $16,5 \mathrm{~b}$ & $2,29 \mathrm{~b}$ & $1,76 \mathrm{~b}$ & $283 \mathrm{~b}$ & $188 \mathrm{~b}$ & $16,3 \mathrm{a}$ & $11,30 \mathrm{a}$ & $22,37 \mathrm{a}$ & $76,24 b$ \\
\hline Baixeira & $18,4 \mathrm{a}$ & $2,61 \mathrm{a}$ & $2,09 \mathrm{a}$ & $318 \mathrm{a}$ & $226 \mathrm{a}$ & $16,4 \mathrm{a}$ & $8,95 \mathrm{~b}$ & $19,30 \mathrm{~b}$ & $79,24 \mathrm{a}$ \\
\hline \multicolumn{10}{|l|}{ Poda apical $^{1}$} \\
\hline 3 folhas & $17,6 \mathrm{a}$ & $2,49 \mathrm{a}$ & $1,97 \mathrm{a}$ & $307 \mathrm{a}$ & $212 \mathrm{a}$ & $16,7 \mathrm{a}$ & $9,84 \mathrm{a}$ & $20,41 \mathrm{a}$ & $78,06 \mathrm{a}$ \\
\hline 5 folhas & $17,3 \mathrm{a}$ & $2,41 \mathrm{a}$ & $1,89 \mathrm{a}$ & $294 \mathrm{a}$ & $202 \mathrm{a}$ & $16,0 \mathrm{a}$ & $10,27 \mathrm{a}$ & $21,15 \mathrm{a}$ & $77,39 \mathrm{a}$ \\
\hline CV (\%) & 8,1 & 9,1 & 8,8 & 5,3 & 5,4 & 5,7 & 12,6 & 4,8 & 0,9 \\
\hline
\end{tabular}

Médias seguidas por letras distintas diferem entre si pelo teste de Tukey a 5\% de probabilidade (average values followed by different letters differ from each other by Tukey test at $5 \%$ of probability); ${ }^{1}$ Poda apical = números de folhas entre a poda apical e o último cacho (number of leaves between the top pruning and the highest cluster). 
Tabela 2. Massa fresca média dos frutos totais (MFMFT), massa fresca média dos frutos comerciais (MFMFC), diâmetro (DIAM), comprimento (COMP) e teor de sólidos solúveis (TSS) dos frutos comerciais de plantas de mini tomate submetidas a dois tipos de condução das hastes e duas podas apicais [average fresh weight of total (MFMFT) and marketable fruits (MFMFC), diameter (DIAM), length (COMP) and total soluble solids content (TSS) of marketable fruits of mini tomato plants submitted to two stem conduction types and two top prunings]. Itatinga, UNESP, 2012.

\begin{tabular}{|c|c|c|c|c|c|}
\hline \multirow{2}{*}{$\begin{array}{l}\text { Condução } \\
\text { das hastes }\end{array}$} & MFMFT & MFMFC & DIAM & COMP & \multirow{2}{*}{$\begin{array}{c}\text { TSS } \\
\left({ }^{\circ} \text { Brix }\right)\end{array}$} \\
\hline & \multicolumn{2}{|c|}{ (g/fruto) } & \multicolumn{2}{|c|}{$(\mathrm{cm})$} & \\
\hline Tradicional & $10,41 \mathrm{a}$ & $9,36 \mathrm{a}$ & $2,27 \mathrm{a}$ & $3,30 \mathrm{a}$ & $7,01 \mathrm{a}$ \\
\hline Baixeira & $8,69 \mathrm{~b}$ & $9,22 \mathrm{a}$ & $2,21 \mathrm{~b}$ & $3,18 \mathrm{~b}$ & $7,08 \mathrm{a}$ \\
\hline \multicolumn{6}{|c|}{ Poda apical $^{1}$} \\
\hline 3 & $9,50 \mathrm{a}$ & $9,25 \mathrm{a}$ & $2,24 \mathrm{a}$ & $3,23 \mathrm{a}$ & $7,02 \mathrm{a}$ \\
\hline 5 & $9,59 \mathrm{a}$ & $9,33 \mathrm{a}$ & $2,24 \mathrm{a}$ & $3,25 \mathrm{a}$ & $7,07 \mathrm{a}$ \\
\hline $\mathrm{CV}(\%)$ & 7,4 & 6,9 & 2,7 & 3,3 & 3,1 \\
\hline
\end{tabular}

Médias seguidas por letras distintas diferem entre si pelo teste de Tukey a 5\% de probabilidade (average values followed by different letters differ from each other by Tukey test at $5 \%$ of probability); ${ }^{1}$ Poda apical $=$ números de folhas entre a poda apical e o último cacho (number of leaves between the top pruning and the highest cluster).

diminui o custo de produção utilizando-se menor quantidade de plantas por unidade de área, visto que o custo de uma muda enxertada é muito grande, aproximadamente $\mathrm{R} \$ 3,50$ no caso do híbrido Sweet Grape enxertado utilizado nesta pesquisa no dia do transplantio (08/12/2011).

Para a massa fresca média dos frutos comerciais, observa-se que não houve diferença significativa entre os tipos de condução de hastes avaliados (Tabela 2). Uma possível explicação para esse resultado é que como foram avaliados somente os frutos comerciais, ou seja, aqueles com massa igual ou superior a cinco gramas, diminuiu-se a amplitude de variação da massa fresca dos frutos devido à seleção e descarte dos frutos pequenos. Além disto, a maior incidência de frutos atacados por pragas no tratamento com condução tradicional ocorreu em frutos graúdos, que seriam classificados como comerciais se fosse considerado apenas a sua massa individual. Isto explica a menor massa média de frutos comerciais em relação à massa de todos os frutos no tratamento com condução tradicional.

Observa-se que o tratamento com condução tradicional das hastes foi superior à condução de "hastes baixeiras" tanto para o diâmetro quanto para dos frutos em plantas da cultivar Laura podadas com duas folhas acima do cacho, quando comparadas a nenhuma ou uma folha. No entanto, conforme discutido anteriormente, estes autores trabalharam com apenas um cacho por planta enquanto na presente pesquisa foram mais de 16.

Segundo Tanaka \& Fujita (1974), em tomateiros de crescimento indeterminado após o aparecimento da primeira inflorescência, observam-se novas inflorescências a cada três folhas. Estes autores denominaram de unidade fonte/dreno o conjunto de três folhas e sua respectiva inflorescência e relataram que quando era removida a inflorescência (dreno) da última unidade fonte/dreno, as folhas (fonte) carreavam seus fotoassimilados para os frutos das unidades localizadas nos estratos inferiores da planta, favorecendo o aumento na massa, comprimento e diâmetro dos frutos. Portanto, esperava-se que a massa média, o diâmetro e o comprimento dos frutos do tratamento onde foram deixadas cinco folhas entre o último cacho e a capação fossem maiores do que no tratamento onde se deixaram apenas três, pois com cinco folhas foi retirada a inflorescência da última unidade fonte-dreno. Porém, esse efeito não foi observado no presente experimento. Uma possível explicação para esse resultado seria o intenso ataque de pragas, com o seu pico ao final do ciclo, que danificaram as folhas reduzindo a área foliar e fazendo com que o potencial fotossintético destas últimas folhas fosse prejudicado. Além disso, o grande número de frutos por cacho (média de 16,3 frutos) pode ter diluído este efeito benéfico para cada fruto individualmente.

$\mathrm{Na}$ presente condução experimental, conclui-se que a condução de duas "hastes baixeiras" favorece a obtenção de maior número de frutos e, consequentemente, maior produção por planta, sem afetar o teor de sólidos solúveis.

\section{AGRADECIMENTOS}

Os autores agradecem à Fazenda Santa Terezinha do Rio Bonito, em 
especial ao Sr. Alex Gordon Lee.

\section{REFERÊNCIAS}

ABRAHÃO C; VILLAS BÔAS RL; BULL LT. 2014. Relação $\mathrm{K}: \mathrm{Ca}: \mathrm{Mg}$ na solução nutritiva para a produção de mini tomate cultivado em substrato. Irriga 19: 214-224.

AGRIANUAL. 2013. Anuário da Agricultura Brasileira. São Paulo: Informações Econômicas FNP. p.456-462.

ALVARENGA MAR. 2013. Tomate: produção em campo, casa-de-vegetação e hidroponia. $2^{\mathrm{a}}$ Ed. Lavras: UFLA. 455p.

CHARLO HCO; SOUZA SC; CASTOLDI R; BRAZ LT. 2009. Desempenho e qualidade de frutos de tomateiro em cultivo protegido com diferentes números de hastes. Horticultura Brasileira 27: 144-149.

DORAIS M; PAPADOPOULOS AP; GOSSELIN
A. 2001. Greenhouse tomato fruit quality. Horticultural Reviews 26: 239-319.

FAO. 2012. Disponível em: <http://faostat3. fao.org/home/index.html\#DOWNLOAD>. Acessado em: 20 de fevereiro de 2013.

FILGUEIRA FAR. 2008. Novo manual de olericultura: agrotecnologia moderna na produção e comercialização de hortaliças. 3. ed. Viçosa: UFV. 421p.

GUIMARÃES MA; SILVA DJH; FONTES PCR; CALIMAN FRB; LOOS RA; STRINGHETA PC. 2007. Produção e sabor dos frutos de tomateiro submetidos à poda apical e de cachos florais. Horticultura Brasileira 25: 265-269.

LOGENDRA LS; GIANFAGNA TJ; SPECCA DR; JANES HW. 2001. Greenhouse tomato limited cluster production systems: crop management practices affect yield. HortScience 36: 893-896.

MACHADO AQ; ALVARENGA MAR; FLORENTINO CET. 2007. Produção de tomate italiano (saladete) sob diferentes densidades de plantio e sistemas de poda visando ao consumo in natura. Horticultura Brasileira 25: 149-153.

MATOS ES; SHIRAHIGE FH; MELO PCT. 2012. Desempenho de híbridos de tomate de crescimento indeterminado em função de sistemas de condução de plantas. Horticultura Brasileira 30: 240-245.

MUELLER S; WAMSER AF. 2009. Combinação da altura de desponte e do espaçamento entre plantas de tomate. Horticultura Brasileira 27: 64-69.

PEEL MC; FINLAYSON BL; Mc MAHON TA. 2007. Updated world map of the KöppenGeiger climate classification. Hydrology and Earth System Science 11: 1633-1644.

TANAKAA; FUJITAK. 1974. Nutri-physiological studies on the tomato plant. IV. Source-sink relationship and structure of the source-sink unit. Soil Science and Plant Nutrition 20: 305-315. 